
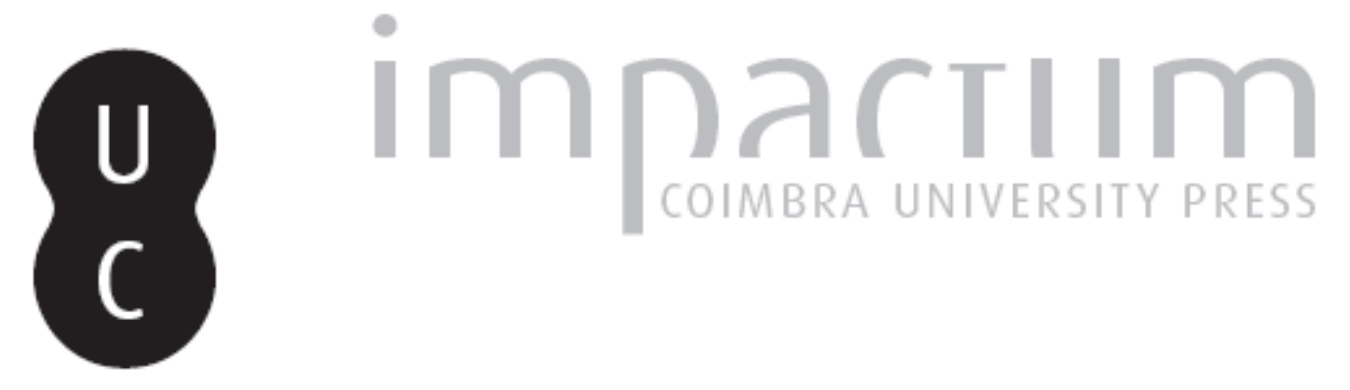

\title{
A nova legitimidade do serviço público
}

Autor(es): $\quad$ Carvalho, Alberto Arons de

Publicado por: Imprensa da Universidade de Coimbra

URL persistente:

URl:http://hdl.handle.net/10316.2/39185

DOI:

DOI:http//dx.doi.org/10.14195/2183-6019_2_2

Accessed : $\quad$ 26-Apr-2023 12:20:13

A navegação consulta e descarregamento dos títulos inseridos nas Bibliotecas Digitais UC Digitalis, UC Pombalina e UC Impactum, pressupõem a aceitação plena e sem reservas dos Termos e Condições de Uso destas Bibliotecas Digitais, disponíveis em https://digitalis.uc.pt/pt-pt/termos.

Conforme exposto nos referidos Termos e Condições de Uso, o descarregamento de títulos de acesso restrito requer uma licença válida de autorização devendo o utilizador aceder ao(s) documento(s) a partir de um endereço de IP da instituição detentora da supramencionada licença.

Ao utilizador é apenas permitido o descarregamento para uso pessoal, pelo que o emprego do(s) título(s) descarregado(s) para outro fim, designadamente comercial, carece de autorização do respetivo autor ou editor da obra.

Na medida em que todas as obras da UC Digitalis se encontram protegidas pelo Código do Direito de Autor e Direitos Conexos e demais legislação aplicável, toda a cópia, parcial ou total, deste documento, nos casos em que é legalmente admitida, deverá conter ou fazer-se acompanhar por este aviso.

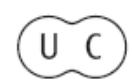


revista de comunicação,

jornalismo e espaço público

2

Periodicidade

Semestral

Imprensa da Universidade de Coimbra Coimbra University Press

\section{mediapolis}

tema

os desafios dos media

de serviço público

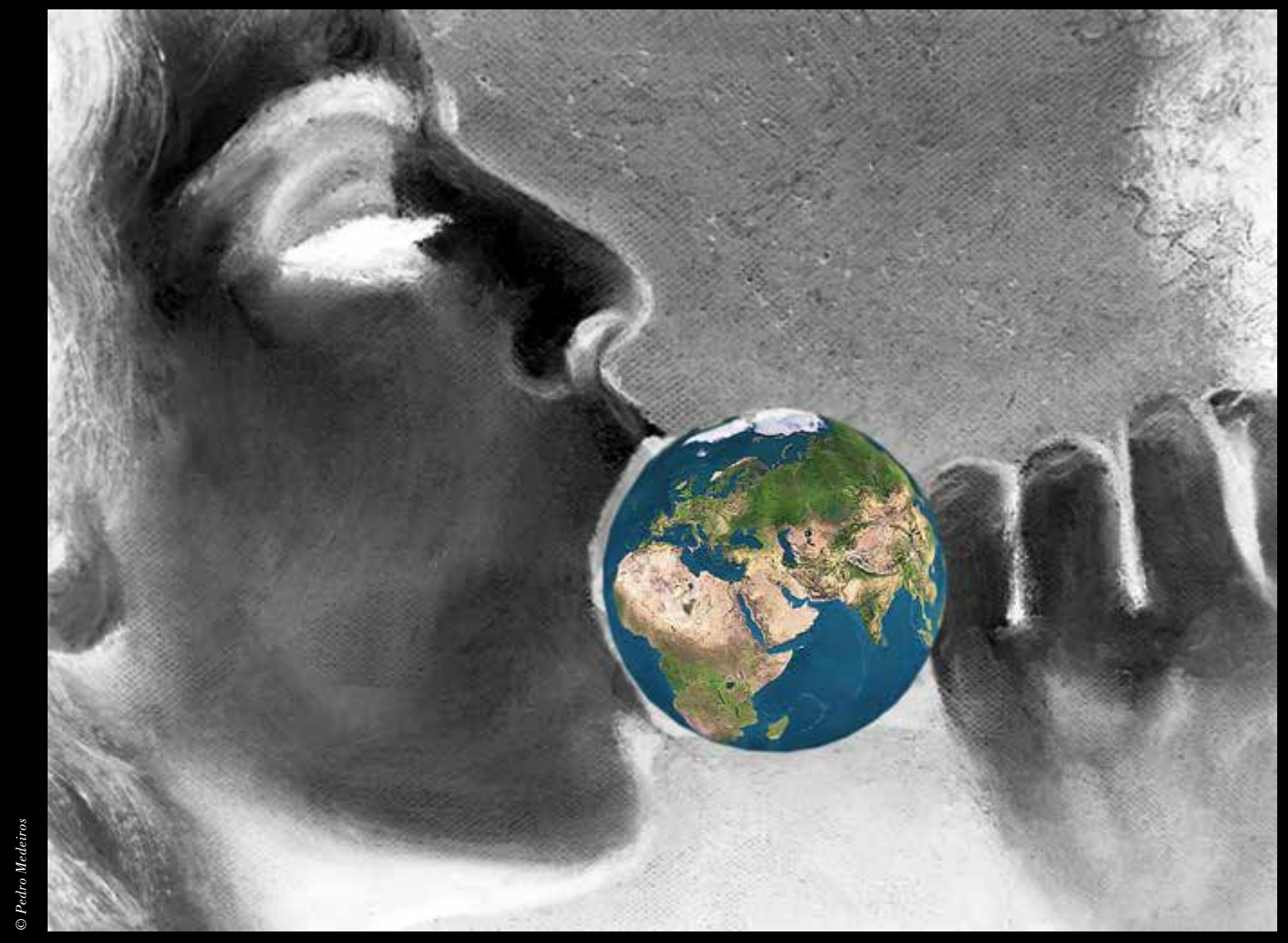




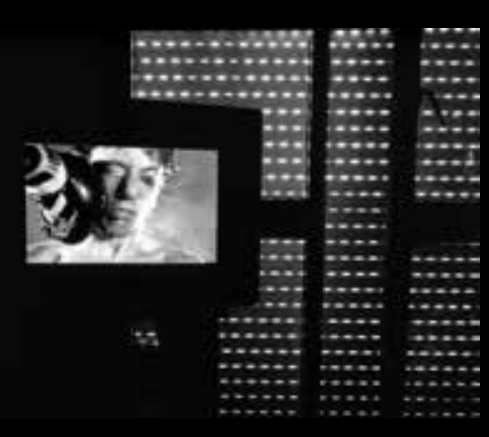




\title{
A nova legitimidade do serviço público
}

\author{
The new legitimacy of the public service
}

\section{Resumo:}

O contexto tecnológico, económico, social e político da televisão mudou muito desde a era em que um operador de serviço público detinha o monopólio da atividade televisiva ou mesmo relativamente ao período em que ele sofria a concorrência de um limitado número de operadores através do espectro radioelétrico. A era digital coloca novos desafios ao serviço público, designadamente o de justificar a sua existência no quadro de uma oferta diversificada e, simultaneamente, rejeitar um papel meramente marginal e suplementar, representar um paradigma de produção e distribuição de conteúdos de qualidade e de abertura à inovação e ao experimentalismo, assumir o papel estratégico de um operador de capitais obrigatoriamente nacionais e oferecer novos canais e serviços, incluindo não lineares interativos.

Palavras-chave: Serviço público, televisão, digital, legitimidade, Portugal

\section{Abstract:}

The technological, economic, social and political context of television has changed a lot since the age where a public service operator held a monopoly on television activity or even since the period in which it faced competition from a limited number of operators using the radio electric spectrum. The digital age presents new challenges to the public service, namely to justify its existence as part of a diversified offer and simultaneously to reject a marginal and supplementary role, to represent a paradigm of production and distribution of quality content and openness to innovation and experimentation, to assume the strategic role of a mandatory national capital operator and offer new channels and services, including interactive non-linear ones.

Keywords: Public service, television, digital, legitimacy, Portugal 
Quando se analisa o serviço público de rádio e de televisão, nomeadamente do ponto de vista da sua legitimidade, importa evitar dois erros demasiado comuns: em primeiro lugar, o de avaliá-lo como se nada tivesse mudado desde o tempo em que havia um monopólio dos operadores públicos; em segundo lugar, confrontar os defensores de um serviço público de rádio e de televisão apenas com os argumentos por estes invocados na era do monopólio, como se não tivessem mudado não apenas os contextos tecnológicos, económicos, sociais e políticos como a própria legitimidade do serviço público na era digital, tal como o reconhecem inúmeros documentos europeus do Conselho, do Parlamento e da Comissão.

Na fase inicial, na era do monopólio, a legitimidade do serviço público de televisão decorria de um conjunto bem diverso de motivos: a continuidade do seu papel relativamente ao das empresas públicas de telecomunicações e de rádio; a escassez das frequências disponíveis; os elevados custos de um operador televisivo e das redes de emissores; a inexistência de uma indústria audiovisual; a utilização da televisão pelo poder político (desde a afirmação das lideranças ou da mera afirmação nacional e da política cultural ao receio da utilização por forças extremistas).

$\mathrm{Na}$ maior parte dos países europeus, os anos 70 e 80 do século passado foram também os do fim desse monopólio do operador público de televisão. Por várias razões: as inovações tecnológicas (por exemplo, a possibilidade de difusão por cabo e por satélite); o desenvolvimento económico; o crescente impacto das televisões com o consequente interesse dos anunciantes; o nascimento da indústria audiovisual, que mais lucraria com a concorrência entre operadores e com o alargamento do seu mercado; a diminuição do papel do Estado na economia; a internacionalização dos investimentos e dos mercados; a difusão transfronteiriça dos canais e o chamado efeito dominó, ou seja, a influência que a experiência, em alguns países, de licenciamento de operadores privados em concorrência com o operador público foi tendo no debate e nas decisões políticas tomadas noutros Estados do Velho Continente.

O fim do monopólio televisivo dos operadores públicos acarretou novas preocupações e desafios que diversos autores analisaram com detalhe e realismo: recordem-se as reflexões de Achille, Richeri e Bustamante em torno daquilo que classificaram, com estes ou outros termos semelhantes, como as crises de legitimidade, funcionamento e financiamento.

A concorrência entre o operador público e novos operadores privados provocaria complexos dilemas aos cidadãos, aos governantes e aos responsáveis pela programação dos operadores públicos.

Os cidadãos eram confrontados com interrogações relacionadas com a utilidade do operador público: para que serve um canal igual aos outros? Porque pagamos um canal que não vemos ou vemos pouco?

Os governantes tinham outro tipo de preocupações: como poderemos aumentar o montante da taxa, se a população já não precisa do operador público para ver televisão? Porque deveremos pagar um operador com estruturas dispendiosas, pesadas e governamentalizadas?

Por sua vez, os responsáveis pelos conteúdos emitidos pelo operador público eram invariavelmente sujeitos a uma escolha bem dilemática: vamos concorrer no terreno dos privados ou construir uma alternativa clara? E, neste caso, que fazer se as audiências 
caírem significativamente? Faz sentido um serviço público para públicos minoritários?

A reflexão produzida nos diferentes Estados europeus, bem como nas instâncias comunitárias, conduziria a uma relegitimação do serviço público televisivo. Afinal, apesar da crescente proliferação de operadores e canais privados, a existência de um operador responsável pelo serviço público justificar-se-ia atendendo sobretudo à continuidade do seu papel regulador, reforçado pela relativa escassez da oferta televisiva disponível a todos os cidadãos.

A legitimidade do serviço público voltaria a ser questionada na era digital. As profundas modificações tecnológicas e na economia dos media imporiam uma nova reflexão sobre o papel do serviço público de televisão. De facto, os limites do mercado - da publicidade, mas também de outras receitas comerciais - são agora bem mais relevantes do que os limites do espectro radioelétrico, agilizados pelas tecnologias digitais. A televisão é agora difundida por diversos meios e recebida em diversos suportes. A oferta televisiva multiplica-se. A fragmentação das audiências diminui substancialmente o efeito de coesão social oferecido pelo operador público, a "praça central" referida por Nissen. Muda substancialmente a forma de consumo da televisão, desde logo nos horários escolhidos (do prime time ao my time, ou seja da vinculação ao horário de emissão escolhido pelos operadores à liberdade de cada um de ver o que quer da programação emitida no momento que escolher!). Depois da taxa e da publicidade comercial, emerge uma terceira forma de pagamento da televisão, a pay $t v$, com o aparecimento de um crescente número de novos canais de acesso condicionado.

Este novo contexto coloca novos desafios ao serviço público, designadamente o de justificar a sua existência no quadro de uma oferta diversificada e simultaneamente rejeitar um papel meramente marginal e suplementar (ou meramente complementar, como erradamente se escreve no texto do projeto de contrato de concessão do serviço público de rádio e de televisão, atualmente em debate).

Ainda a propósito do debate atualmente em curso, importa sublinhar o seguinte: o operador de serviço público não pode limitar-se a transmitir apenas os conteúdos sem interesse comercial para os operadores privados; não pode acantonar-se num gueto de conteúdos culturais e pedagógicos que lhe retirarão toda a audiência, papel regulador e legitimidade; não será possível exigir aos portugueses que paguem uma contribuição para o audiovisual (CAV) de um operador que se limite a obter uma influência marginal! $O$ conceito de modelo europeu de serviço público, sobre o qual mais de 20 documentos de instâncias diversas como a Comissão Europeia, o Parlamento Europeu ou o Conselho da Europa têm refletido, não consiste apenas nos conteúdos mais eruditos. Pelo contrário, a ideia de indivisibilidade do serviço público, conceito que deveria estar no contrato de concessão em apreciação, constitui uma das matrizes do modelo europeu, pressupondo que também o entretenimento de qualidade, por exemplo, deve integrar o leque de conteúdos dos operadores públicos.

No entanto, a RTP, incluindo naturalmente os seus principais serviços de programas de rádio e de televisão, não pode concorrer com os operadores privados no seu próprio terreno - visar apenas maximizar audiências e receitas publicitárias, ignorando os públicos 
minoritários, não oferecer uma programação distintiva, com qualidade, mesmo nos programas de entretenimento, nem fazer contraprogramação, não cumprir os horários de programação anunciados. A propósito, refira-se o condenável procedimento recente dos dois operadores privados generalistas que começam os noticiários da noite quase 2 minutos antes da hora anunciada, um deles até escondendo o relógio até às 20 horas.

Mas existem outros desafios ao operador de serviço público:

- Representar um paradigma de produção e de distribuição (sublinho, não apenas de distribuição...) de conteúdos de qualidade. Aproveito para manifestar a minha discordância face à projetada extinção do setor de produção da RTP. A capacidade de produção própria pela RTP representa uma garantia de diversidade, de qualidade e de pluralismo. A RTP não deveria estar prisioneira dos preços de mercado e dos conteúdos da oferta dos produtores independentes. Numa altura em que a televisão é cada vez mais consumida como serviço não linear, a chancela da qualidade da produção RTP deveria representar uma garantia incontornável.

- Representar a abertura à inovação e ao experimentalismo, e ao respetivo risco, em serviços, conteúdos, tecnologias e formas de consumo.

- Assumir a importância e o papel estratégico de um operador de capitais obrigatoriamente nacionais (por serem públicos), garantia que não existe nos operadores privados. Recorde-se, aliás, a experiência em alguns países da Europa de Leste a seguir à implosão da União Soviética em 1989, onde o operador público era o único de capitais nacionais, face à forte presença de operadores privados com capitais estrangeiros.

- Assegurar a independência face ao poder político, rejeitando a antiga tradição portuguesa (ou mesmo latina...mas não europeia) de a televisão do Estado se tornar inevitavelmente a televisão do Governo, aperfeiçoando o modelo de governação criado através de diversas medidas nos últimos 20 anos - criação do Conselho de Opinião, inamovibilidade dos gestores, papel dos dois (sublinho dois) provedores e da ERC, autonomia editorial da informação e da programação face ao Conselho de Administração, sem esquecer o decisivo papel dos jornalistas em assegurar essa independência. A este propósito, direi que a criação de um conselho, como o projetado CGI, não profissional nem especializado ou a tempo inteiro, que distancie o Governo da empresa parece ter mais inconvenientes do que vantagens. Reconheço a preocupação em afastar as suspeitas sobre a governamentalização da RTP, mas, a este propósito, deveriam ser analisadas as dúvidas suscitadas na Grã-Bretanha pela experiência do $B B C$ Trust. - Garantir a independência face a interesses económicos privados.

Importa refletir um pouco mais sobre este tema, que se transformou numa matéria tabu em Portugal. É cada vez mais evidente a submissão de órgãos de comunicação a interesses privados que condicionam a liberdade editorial dos seus jornalistas. E é inaceitável que se fale tanto em assegurar a independência da comunicação social face ao poder político e se esqueça o poder económico. Pergunto: não tem sido evidente o facto de vários órgãos 
de comunicação social condicionarem a sua orientação editorial face aos governos e a alguns governantes em função de interesses, legítimos, mas privados, dos seus grupos empresariais? Será tranquilizador saber que, ao lado de grupos de comunicação social que aspiram legitimamente a ter sucesso e lucros no setor, há outros que existem para ter proveitos e outras vantagens não no setor da comunicação social mas pela influência social, económica e política que têm através dele? Será aceitável que existam grupos de comunicação social de que não se conhecem os seus acionistas, situados em obscuros offshores, e que não aceitam colaborar, como a legislação impõe, com quem tem de assegurar a transparência da propriedade das empresas de comunicação social? Que comentário merecerá o facto de um operador de televisão, há algumas semanas, poucos dias depois da tragédia de Lampedusa, ter divulgado durante o seu principal noticiário uma invulgar nota editorial não sobre essa tragédia mas sobre um documento da ERC em que, na sequência de um texto da Autoridade da Concorrência com conclusões idênticas, se formulava a mera opinião segundo a qual o Governo poderia, se o entendesse e mediante determinados pressupostos, colocar novos canais de serviço público na TDT? Ainda por cima, essa nota editorial deturpava o documento da ERC...

Mas regressemos aos desafios ao operador de serviço público nesta era digital:

- Assegurar a previsibilidade da gestão, mediante planos plurianuais.

- Manter-se fiel e atento aos inúmeros (mais de 20!) documentos internacionais sobre o serviço público que têm sido aprovados nas últimas duas décadas, nomeadamente, pela Comissão Europeia, pelo Conselho da Europa e pelo Parlamento Europeu. Existe em Portugal uma inaceitável ignorância sobre o vasto consenso europeu relativamente ao papel do serviço público na era digital.

- Possibilidade de oferecer novos canais e serviços não lucrativos, quer serviços lineares generalistas, quer serviços para audiências específicas, quer serviços não lineares interativos. A generalidade dos operadores europeus de serviço público tem muitos canais temáticos na oferta em aberto da TDT (na Europa, 13\% dos canais pertencem aos operadores públicos, mas se tivermos em conta a oferta da TDT em aberto, essa percentagem sobe para 25\%; recorde-se, por outro lado, que os operadores públicos tiveram um papel decisivo no arranque da TDT (exemplos da Espanha e da Grã-Bretanha). E que todos os operadores públicos europeus têm um canal temático informativo. A RTP não pode também ignorar a oferta no mobile e nos websites. E deveria encarar este tema como uma das suas prioridades, na medida em que a sua viabilidade económica o permita.

\section{Bibliografia}

Achille, Y. (1994). Les Télévisions Publiques en Quête d'Avenir. Grenoble: Pug.

Bustamante, E. (1999). La Televisión Económica. Barcelona: Gedisa.

Nissen, C. (dir.) (2006). Faire la Différen$c e:$ La radiodiffusion de service public dans le paysage audiovisual européen. Londres: John Libbey Publishing.

Richeri, G. (1993). La TV Che Conta. Bolonha: Baskerville. 